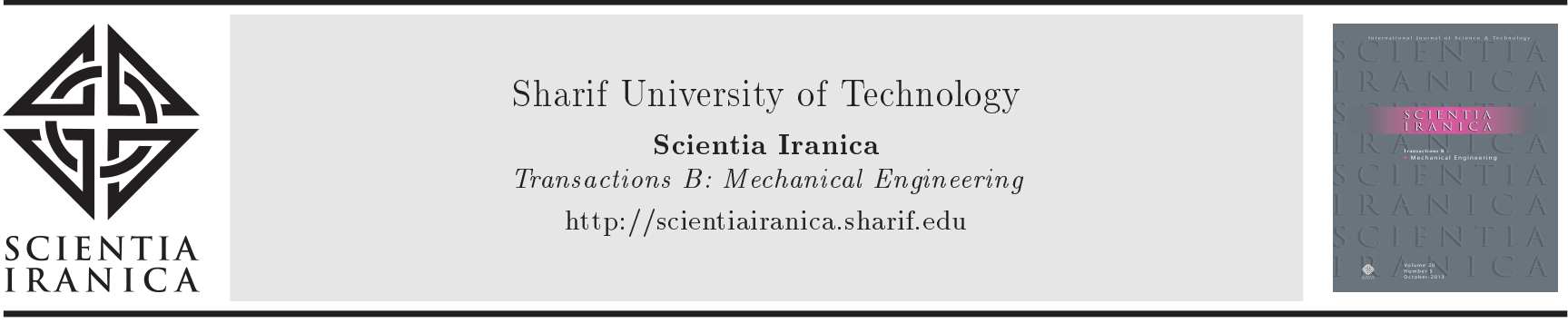

\title{
Mechanical safety analysis of the gas lift completion string used for a high-pressure sandwich layer
}

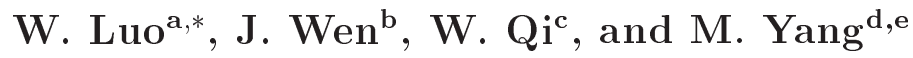 \\ a. Petroleum Engineering Institute of Yangtze University, Wuhan, Hubei 430100, China. \\ b. Logging Technology and Engineering Research Institute of Yangtze University, Jingzhou, Hubei 434000, China. \\ c. Research and Development Center, Tuha Oilfield Company, CNPC, Shanshan, Xinjiang, 838202, China. \\ d. Research Institute of Exploration and Development, Tuha Oilfield Company, PetroChina, Hami, Xinjiang 839009, China. \\ e. CNPC AMERICA LTD., Venezuela.
}

Received 2 January 2018; received in revised form 9 February 2021; accepted 2 August 2021

\section{KEYWORDS}

High salt;

High-pressure

sandwich;

Dual tube completion;

System reliability;

The squeeze strength.

\begin{abstract}
This study examines the mechanical safety of a gas lift completion string in a certain oilfield, Algeria 438B block, having complex geological characteristics (a high salt and high-pressure sandwich). When an annulus is not supported within fluid column after unloading by using conventional single-tube gas lift completion with positive lift oil production, inner pressure is so low that the pressure differential between the annulus and external casing is very large, which may damage the casing. Hence, a dual tube completion annulus filled with fluid that can resist pressure was used to overcome this problem in adjacent blocks using a gas lift production string with positive and reverse lift oil. However, this technology is complex and characterized by poor system reliability, large construction costs, and maintenance difficulty. By considering the three aspects of a casing string, squeeze strength, tensile strength, and internal pressure strength, a gas lift completion string with dual concentric tubes and positive lift was preferably selected under conditions that were verified to be safe for production and a shut-in state. This gas lift completion string design was shown to be feasible and had no problem of completion string in adjacent blocks.
\end{abstract}

(C) 2022 Sharif University of Technology. All rights reserved.

\section{Introduction}

To ensure the safety of drilling process and the normal operation of oil wells after borehole completion, borehole casing is primarily used for supporting a borehole wall during drilling process and after borehole completion. The design and strength checks of each well are determined according to different drilling depths, geological conditions, and well trajectory. The deeper

*. Corresponding author. Tel.: +86 18690205835 E-mail addresses: luoruichang@163.com (W. Luo); 187008098@qq.com (W.Qi);298111526@qq.com (M. Yang)

doi: $10.24200 /$ sci. 2021.50161 .1543 the drilling depth, the more complex the geological conditions and wellbore trajectory. The larger the number of factors influencing a casing string, the greater the number of difficulties in the casing string design and strength check. Many related studies, both at home and abroad, on casing design and strength check have been conducted in different conditions. The following are representative reports, especially in the high-pressure environment. Tian et al. [1], Wang [2], Li [3], Zhou [4], Zhang [5], and Qu and Jin [6] studied the strength analysis of deep well casings. Zou [7] and Wang [8] conducted security string mechanics analysis on high-temperature and high-pressure wells. Wu [9] conducted a casing mechanical analysis and the safety evaluation of depleted gas storage reservoirs. The 
safety of an oil well casing string under the condition of sustained casing pressure was evaluated by different methods [10, 11]. Stability analysis was conducted by numerical simulation in the case of drilling in deep water gas hydrate-bearing formations [12].

There are also some studies on the mechanical analysis of oil well string after changing environmental conditions. The collapsing test was performed for cemented casing under non-uniform load (NFL) by adopting self-developed testing equipment, by which the radial deformation of cemented casing and damage rules of cement sheath were measured and the stressstrain laws of cemented casing were obtained during the testing process by the electrical method [13].

Past studies reveal that well integrity barriers are highly impacted by cement carbonation and casing corrosion processes [14], fluid migration [15], in-situ conditions, cement, and casing mechanical properties. For instance, variation in the temperature or chemical changes will affect the extent of corrosion; hence, a comprehensive design and monitoring system is essential to understanding the well integrity issues clearly. Kiran et al. [16] presented a broad review of research and field experiences related to well integrity.

Based on the borehole condition and field operation data of this well, the borehole pressure field variation initiated by lost circulation in the low-pressure formation was analyzed from the perspective of dynamics. Then, the variation of the pattern of differential pressure inside and outside the well bore at different time intervals was depicted, and the primary cause of such complication was theoretically revealed [17].

Based on PSC jet theory, theorem and similarity law, a pressure field model of oil\&gas wellbore during PSC explosion is presented and its important parameters are discussed by numerically simulating the evolution process of perforation overpressure using the nonlinear finite element software LS-DYNA combined with the ALE and AMR techniques. On the basis of the above work, a simulation model for the actual wellbore overpressure analysis is established and the mechanism of the overpressure evolution is analyzed [18].

To investigate the environmentally assisted cracking performance of $\mathrm{C} 110$, a series of tests were conducted including the basic mechanical property test, the electrochemical corrosion test, the Double Cantilever Beam test (DCB), and the four-point bending test. The results indicate that cold hardening increases the yield strength, reduces the impact toughness, and degrades sulfur-resistance, which greatly increases the potential risk to the integrity of the wellbore [19].

In addition, there are also some related works about gas lift completion strings in oilfield. Grassick et al. [20,21] demonstrated how FMEA (Failure Mode and Effect Analysis) and FTA (Fault-Tree Analysis) were used to help design North Sea well completions and how dynamic simulation modeled complex systems realistically to allow for a comparison of designs and to provide insights into gas-lift completion strings' operating availability and component-testing frequencies.

Nonetheless, the checks of casing collapse, tensile strength, and resistance to internal pressure are the most basic processes of casing design along with a strength check for selecting a suitable stage casing configuration $[22,23]$. Considering the complicated geological characteristics of high salt and high-pressure lamination of the oilfield of the Algeria 438B block, very low inner pressure causes a high differential pressure between the inside and outside, which may lead to casing damage when no support is present within the fluid column after unloading using a conventional single-tube gas lift completion with positive lift oil production. The squeeze strength, tensile strength, and resistance to internal pressure strength should be checked for the gas lift completion string with dual concentric tubes and positive lift, which was preferably selected through the verification calculation of the production capacity and water injection capacity.

\section{Oilfield survey and development difficulties}

\subsection{Oilfield survey}

The buried depth of reservoir in Algeria 438B block oilfield ranges from $3500 \mathrm{~m}$ to $4200 \mathrm{~m}$. Reservoir temperature is between $104^{\circ} \mathrm{C}$ and $108^{\circ} \mathrm{C}$ and the geothermal gradient is $2.29^{\circ} \mathrm{C} / 100 \mathrm{~m}$. The reservoir belongs to low-temperature reservoir. The original formation pressure of the reservoir was from $50 \mathrm{MPa}$ to $60 \mathrm{MPa}$. The saturation pressure is from $25 \mathrm{MPa}$ to $30 \mathrm{MPa}$ and the average pressure factor is 1.45 . The reservoir is classified as an abnormal high-pressure reservoir. The properties of the reservoir's crude oil are relatively good. The reservoir has "five high two low" characteristics, meaning a high original dissolved oilgas ratio, high volume factor, high saturation pressure, high compression coefficient, high shrinkage rate of crude oil, low crude oil density, and low viscosity of crude oil. The original fluid dissolved oil-gas ratio of the reservoir is $180 \mathrm{~m}^{3} / \mathrm{m}^{3}$. The oil volume factor is between 1.45 and 1.65 . The crude oil viscosity in the reservoir under the saturation pressure is between 0.312 and $0.363 \mathrm{mPa} . \mathrm{s}$. The crude oil formation density is between 0.629 and $0.658 \mathrm{~g} / \mathrm{cm}^{3}$, and the degassed oil density is between 0.819 and $0.833 \mathrm{~g} / \mathrm{cm}^{3}$. The shrinkage rate of the crude oil reservoir is between 40.4 and $44.4 \%$. The reservoir belongs to the typical unsaturated jet black reservoir.

The composition of natural gas is given priority, with methane accounting for $56.7 \%$ to $66.1 \%$ of the total composition. The total $\mathrm{C}^{1-3}$ components account for $87 \%$ to $88 \%$ and $\mathrm{CO}_{2}$ accounts for 0.20 to $0.54 \%$; 
no $\mathrm{H}_{2} \mathrm{~S}$ is present. The relative density of natural gas is 0.88 and the pseudo critical temperature is $252 \mathrm{~K}$.

\subsection{Oilfield development difficulties}

The difficulties of oilfield development are as follows:

1. The well salt composition is a major problem that greatly restricts oilfield production. The total salinity of formation water is high and the formation water is of the $\mathrm{CaCl}_{2}$ type. Due to the high salinity of formation water, salt-scale blockages are present near the wellbore zone, the perforating hole, the pipe string, and certain parts such as the nozzle. The blockages cause a decrease or a complete stop in oil production and, seriously, affect the normal production of oil wells. To a certain extent, oil production can return to normal levels after measures to clean salt blockages are undertaken;

2. The well involves an abnormal formation pressure segment. Oil well drilling meets an abnormal pressure pure salt layer and a gypsum layer at depths between $2500 \mathrm{~m}$ and $3500 \mathrm{~m}$. The drilling fluid density is $1.9 \sim 2.0 \mathrm{~g} / \mathrm{cm}^{3}$. To avoid collapsing deformation of production casing, which is a part of a string above $3500 \mathrm{~m}$, an abnormal pressure segment of wellbore must maintain sufficient pressure to protect the production casing.

\section{Completion string configuration and the production type of the gas lift}

Casing perforation completion is recommended for a new vertical well. Slotted liner completion or casing perforation completion is recommended for a new horizontal well. Regional regulations require that freshwater and rock salt layers be blocked off separately using a casing to ensure regional geological safety for the following reasons: the freshwater layer that developed at the shallow block between 200 and $300 \mathrm{~m}$; the gypsum layer that developed mostly near $800 \mathrm{~m}$; and the formation collapse caused by the dissolution of the rock salt layer, which occurred because of the freshwater layer.

\subsection{The completion string and production type of the adjacent area which has the same block properties}

Figure 1a shows a vertical well as an example. If no rock salt formation was present, then one less casing layer would be required. The well is salted easily due to the high total salinity of formation water. A certain proportion of water or salt inhibitors can be added to solve the wellbore salt problem. Hence, a common gas lift well completion string and the production process of wells with salt and without salt at adjacent blocks are shown in Figures 2 to 4, respectively. These figures show that the oil well tube string maintains pressure balance in the high-pressure formation by injecting water into annulus. Hence, the strategy of water injection maintains pressure balance between the inside and outside of casing and prevents casing damage.

\subsection{The new design completion string and production type of Algeria $438 B$ block oilfields}

To increase system reliability and reduce the difficulty of construction and maintenance for Algeria 438B block production targets simultaneously, a new and preferable design for the casing completion string was obtained. This design is shown in Figure 1b, revealing that a $7^{\prime \prime}$ production casing layer is added to the new completion string that does not extend to the wellhead, showing that the tail hanging pipe size has been adjusted accordingly. The simulation of gas lift production was conducted under the conditions of a new completion string. Eventually, it was determined that a $3-1 / 2$ " production string and a $3 / 4$ " concentric water injection string should be combined for production. This combined string is an open string. The design, as shown in Figure 5, can meet the requirements of artificial lift production targets and injected water volume.

\section{The strength adaptability analysis of the new completion string}

The force analysis of the pipe string along the way or a certain part is a common method for our research. For instance, since the production casing is cemented all the way up to the inter-mediate casing in the vertical section of the well, the in-situ stress can only act on the intermediate casing and not directly on production casing. Based on this situation, an analytical model considering the well completion steps is established to study the integrity of cement sheath as a two-layer casing-cement system [24].

The oil wells of Algeria 438B block oilfield experience abnormal pressure in pure salt layer and a gypsum layer at depths of $2500 \mathrm{~m}$ to $3500 \mathrm{~m}$ in drilling process, and the density of the drilling fluid is between 1.9 and $2.0 \mathrm{~g} / \mathrm{cm}^{3}$. When the gas lift performed by annulus injection gas is positive, a casing collapse accident may occur. Therefore, it is necessary to determine the safe lift depth of a new gas lift string. To check the collapse, the tensile load, and resistance to internal pressure of the casing, the production casing can be simplified, as shown in Figure 6. First, the internal and external pressures of the chosen string are analyzed and then, the extension strength of the string is checked in the following. 




Figure 1a. The string for the areas including freshwater and rock salt layers: A common casing well completion string for the adjacent area. 


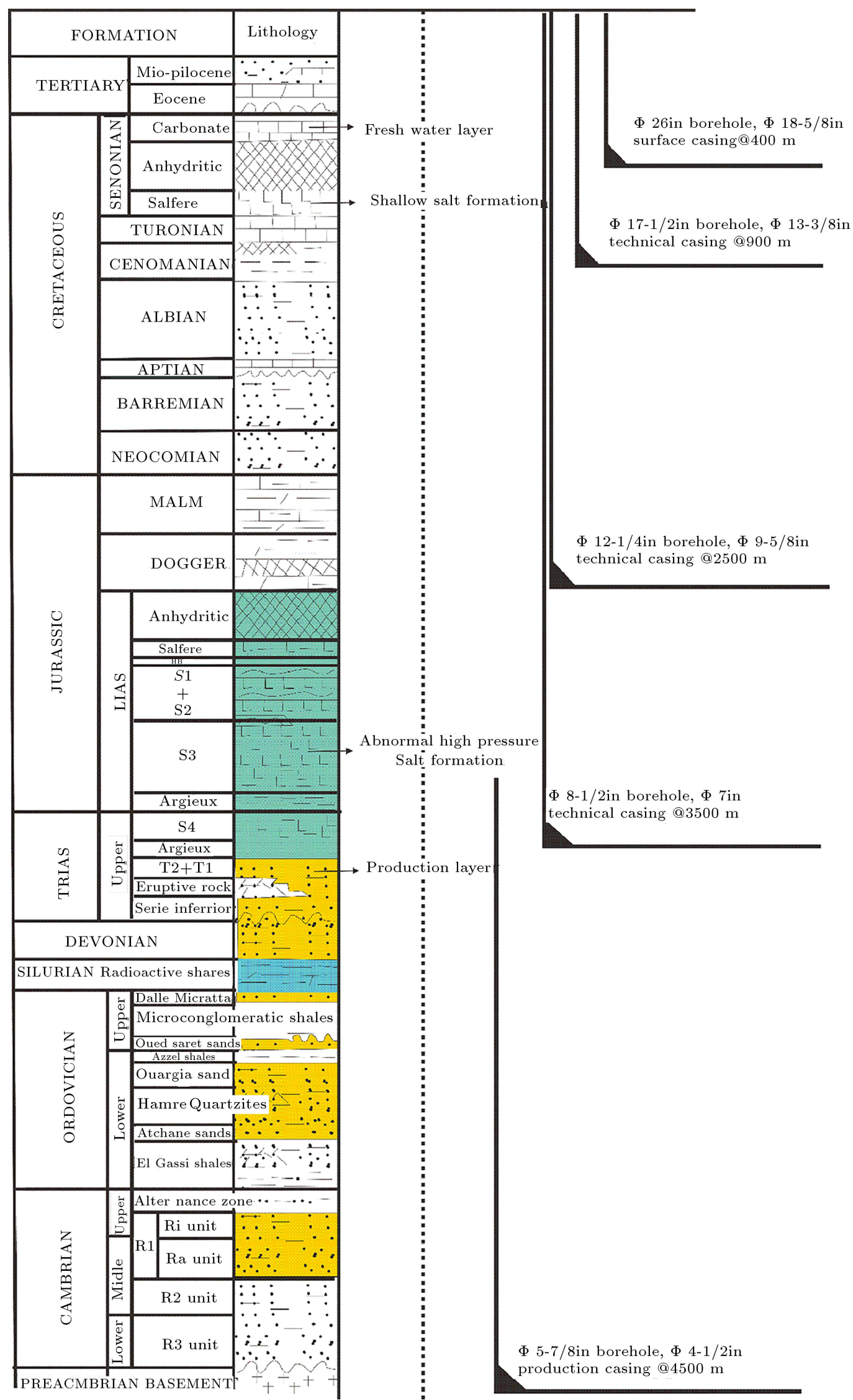

Figure 1b. The string for the areas including freshwater and rock salt layers: A new casing completion string for the Algeria 438B block field. 


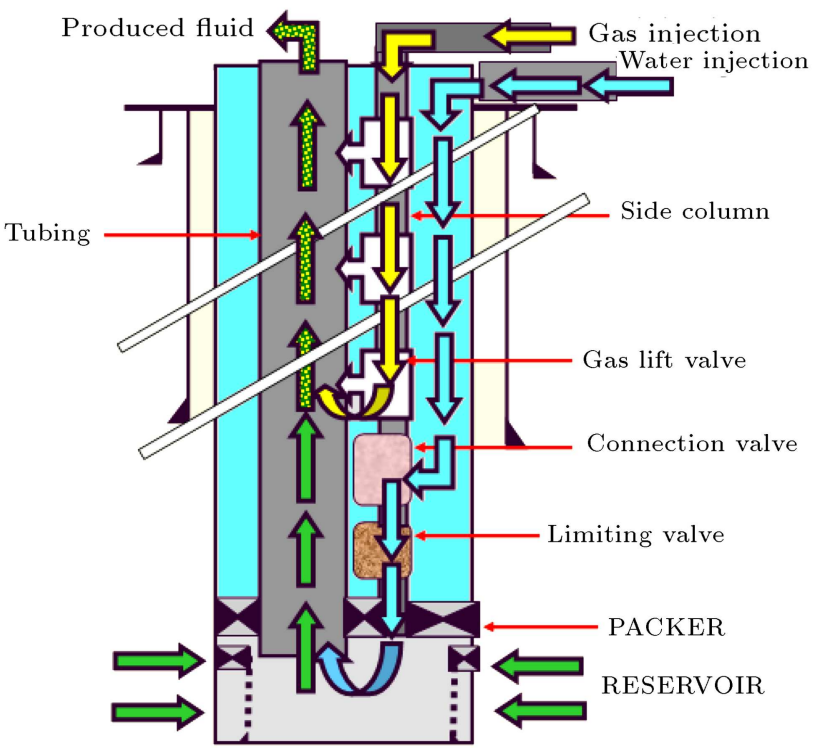

Figure 2. The gas lift completion string and the production process of wells with water.

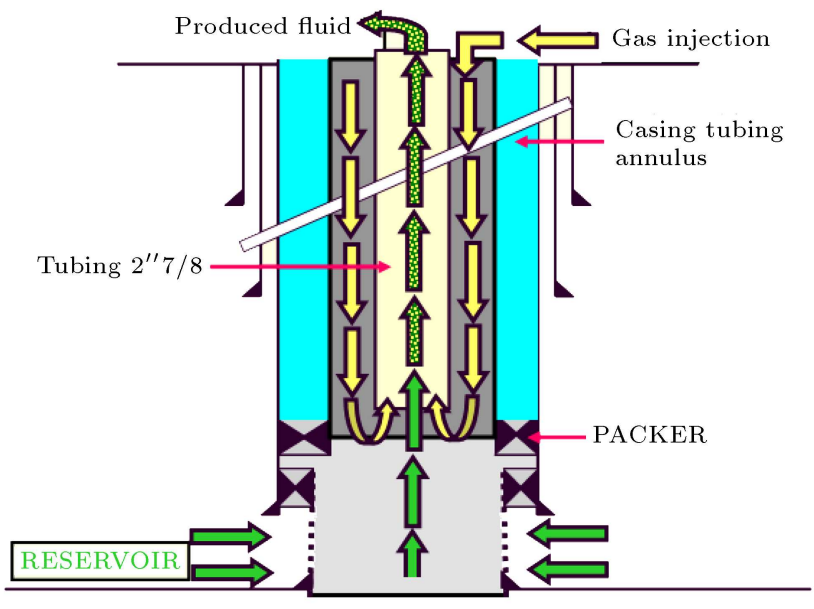

Figure 3. The gas lift completion string with positive lift oil and the production process of wells without water.

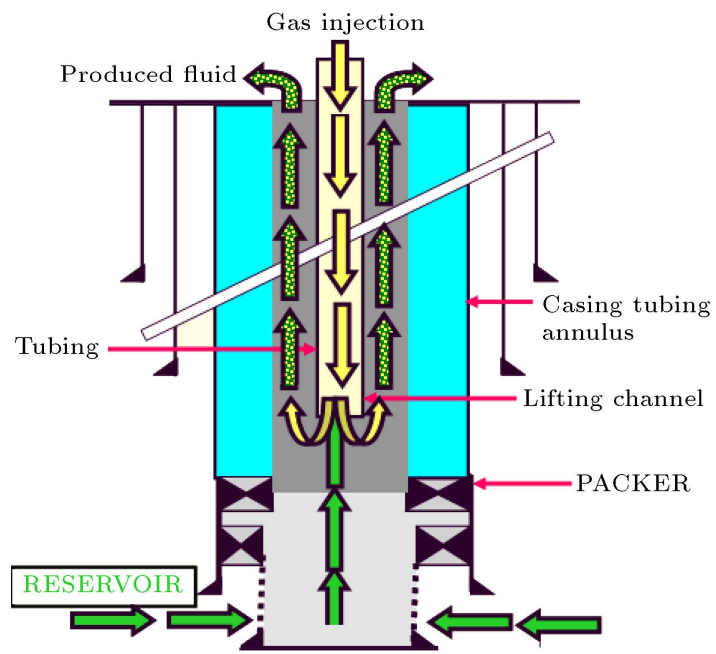

Figure 4. The gas lift completion string with reverse lift oil and the production process of wells without water.

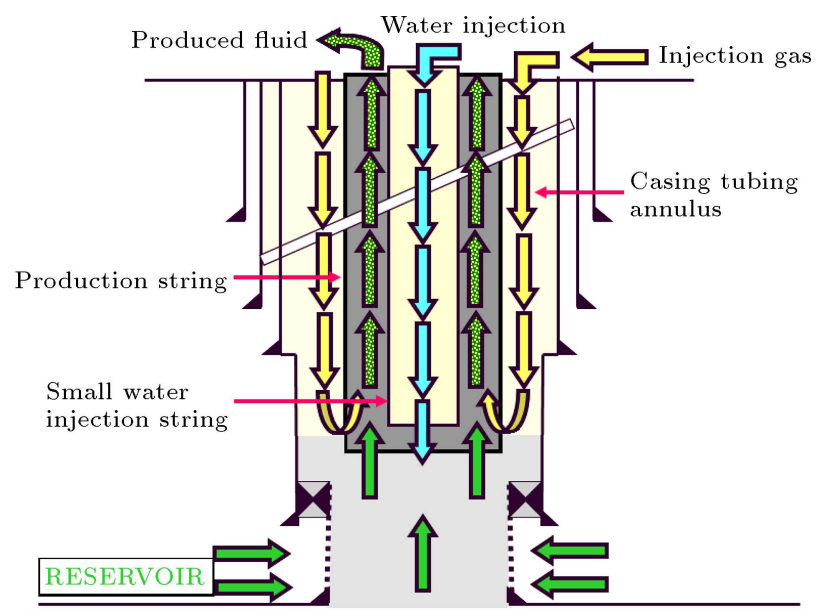

Figure 5. The new gas lift completion string and the production process of wells with water.

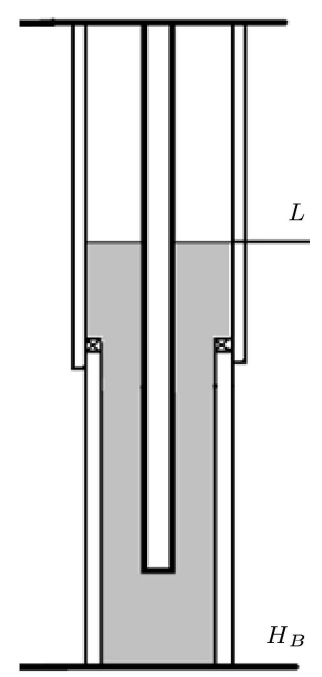

Figure 6. Analysis of the external load of the string.

\subsection{Analysis and calculation of the internal and external pressures of the string}

4.1.1. Analysis and calculation of the external load of the string

Calculation of the external pressure. The cement in the annulus solidifies in the gas lift production process, and the cement ring should support the casing while it is under external pressure. However, this value is difficult to calculate accurately. In view of security, the external pressure of the cement ring is calculated by the drilling fluid column pressure as follows:

$$
P_{o}=\rho_{1} g H \text {. }
$$

Using SI units, Eq. (1) becomes:

$$
P_{o}=\rho_{1} H / 101.97 \text {. }
$$

In Eqs. (1) and (2), $g$ is the acceleration of gravity with a value of $9.807 \mathrm{~kg} . \mathrm{m} / \mathrm{s}^{2} ; \rho_{1}$ is the well killing 
fluid density with units of $\mathrm{g} / \mathrm{cm}^{3} ; H$ is the depth in meters; and $P_{o}$ is the external pressure with units of $\mathrm{MPa}$.

Calculation of the internal pressure. In the gas lift production process, the internal pressure above the gas injection point is the production casing pressure of the oil well and the internal pressure below the lift depth is the sum of the fluid column pressure and the production casing pressure. That is,

$$
\begin{cases}P_{i b}=P_{t} & (0 \leq H \leq L) \\ P_{i b}=\rho_{2}(H-L) / 101.97+P_{t} & \left(L \leq H \leq H_{B}\right)\end{cases}
$$

In Eq. (3), $\rho_{2}$ is the liquid density in the pipe with units of $\mathrm{g} / \mathrm{cm}^{3} ; L$ is the depth of the gas injection point with units of $\mathrm{m} ; P_{i b}$ is the internal pressure with units of $\mathrm{MPa} ; P_{t}$ is the well production casing pressure with units of $\mathrm{MPa}$; and $H_{B}$ is the depth of the reservoir, which is $3500 \mathrm{~m}$.

In the shut-in state after gas lift production, which is the worst situation, the production casing pressure is zero and the internal pressure is the static fluid column pressure in the tube generated by the formation pressure. That is:

$$
\begin{cases}P_{i b}=0 & \left(0 \leq H \leq L_{s}\right) \\ P_{i b}=\rho_{2}\left(H-L_{s}\right) / 101.97 & \left(L_{s}<H \leq H_{B}\right)\end{cases}
$$

In Eq. (4), $L_{s}$ is the depth of the static liquid surface in metric units.

Calculation of the effective external pressure. The effective external pressure is the differential pressure between the external and internal pressures. That is:

$$
P_{o e}=P_{o}-P_{i b} \text {. }
$$

In the gas lift production situation, Eq. (3) is substituted into Eq. (5) resulting in:

$$
\begin{cases}P_{o e}=\rho_{1} H / 101.97-P_{t} & (0 \leq H \leq L) \\ P_{o e}=\frac{\rho_{2} L-\left(\rho_{2}-\rho_{1}\right) H}{101.97}-P_{t} & \left(L \leq H \leq H_{B}\right)\end{cases}
$$

In the shut-in state, Eq. (4) is substituted into Eq. (5), and Eq. (5) is simplified to:

$$
\begin{cases}P_{o e}=\rho_{1} H / 101.97 & \left(0 \leq H \leq L_{s}\right) \\ P_{o e}=\frac{\rho_{1} H-\rho_{2}\left(H-L_{s}\right)}{101.97} & \left(L_{s} \leq H \leq H_{B}\right)\end{cases}
$$

\subsubsection{Safety lift depth calculation of the newly selected gas-lift string}

Note that $\rho_{1}$ is greater than $\rho_{2}$. For the situation in which the lift depth does not reach the reservoir, the effective external pressure is shown in Figure 7 and is based on Eq. (6). For the situation in which the lift depth reaches the reservoir, the effective external pressure is shown in Figure 8. Therefore, the maximum effective external pressure is the effective external pressure in the reservoir and the formula for this situation is as follows:

$$
P_{o e}=\frac{\rho_{1} H_{B}-\rho_{2}\left(H_{B}-L\right)}{101.97}-P_{t} .
$$

The effective external pressure is shown in Figure 9 under the shut-in condition based on Eq. (7). The maximum effective external pressure is the effective

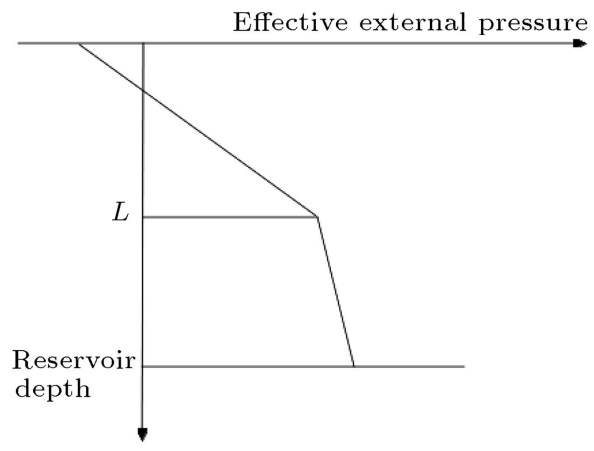

Figure 7. The relationship between the effective external pressure and the depth when the lift depth does not reach the reservoir.

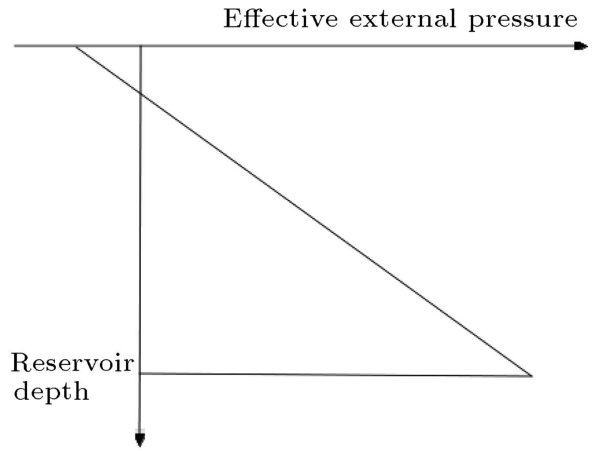

Figure 8. The relationship between the effective external pressure and the depth when the lift depth reaches the reservoir.

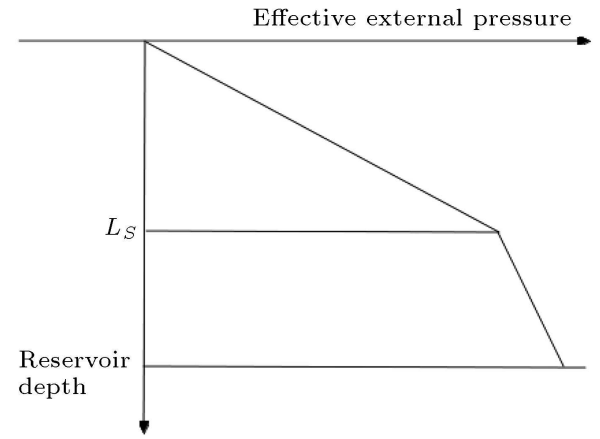

Figure 9. The relationship between the effective external pressure and the depth when the well is shut-in. 
external pressure in the middle reservoir when the reservoir pressure is reduced to the lowest value of the whole development cycle, and the equation for this situation is:

$$
P_{o e}=\frac{\rho_{1} H_{B}-\rho_{2}\left(H_{B}-L\right)}{101.97} .
$$

To avoid the casing collapse problem caused by the oversized lift depth when the gas lift is produced via tubing and an injecting gas annulus, $P_{o e} \leq \frac{P_{r}}{K_{c}}$ is required. Then, the maximum pressure is:

$$
\left.P_{o e}\right|_{\max } \leq \frac{P_{r}}{K_{c}}
$$

When gas lift production is used, it can be shown that:

$$
\frac{\rho_{1} H_{B}-\rho_{2}\left(H_{B}-L\right)}{101.97}-P_{t} \leq \frac{P_{r}}{K_{c}} .
$$

Simplifying Eq. (11) results in:

$$
L \leq \frac{\rho_{2}-\rho_{1}}{\rho_{2}} H_{B}+101.97 \frac{P_{t}}{\rho_{2}}+101.97 \frac{P_{r}}{K_{c} \rho_{2}}
$$

Then, it can be shown that:

$$
L_{\max } \leq \frac{\rho_{2}-\rho_{1}}{\rho_{2}} H_{B}+101.97 \frac{P_{t}}{\rho_{2}}+101.97 \frac{P_{r}}{K_{c} \rho_{2}} .
$$

In the shut-in state of the well, the equation becomes:

$$
\frac{\rho_{1} H_{B}-\rho_{2}\left(H_{B}-L_{s}\right)}{101.97} \leq \frac{P_{r}}{K_{c}}
$$

Simplifying Eq. (14) becomes:

$$
L_{s} \leq \frac{\rho_{2}-\rho_{1}}{\rho_{2}} H_{B}+101.97 \frac{P_{r}}{K_{c} \rho_{2}} .
$$

Then:

$$
L_{s \max } \leq \frac{\rho_{2}-\rho_{1}}{\rho_{2}} H_{B}+101.97 \frac{P_{r}}{K_{c} \rho_{2}} .
$$

Therefore, $L_{\max }$ is the maximum safe lift depth when the well is produced by gas lift, and $L_{s \max }$ is the minimum liquid surface depth of the static liquid surface that ensures safety when the well is in the shut-in state.

In Eq. (16), $P_{r}$ is the extrusion strength that can be obtained using a table with units of $\mathrm{MPa} ; K_{c}$ is the collapsing safety factor of the casing, and the general value is from 1.05 to 1.10 . According to the drilling test manual and oil test technology standard, this value is 1.105. However, $K_{c}$ should be determined by the degree of casing wear according to the well cementing.
Table 1. Calculation of the maximum safe lift depth when produced by a gas lift.

\begin{tabular}{lc}
\hline \multicolumn{1}{c}{ Parameters } & Value \\
\hline Reservoir depth, $H_{B} / \mathrm{m}$ & 2500 \\
Well killing fluid density, $\rho_{1}\left(\mathrm{~g} / \mathrm{cm}^{3}\right)$ & 1.25 \\
Tubing fluid density, $\rho_{2}\left(\mathrm{~g} / \mathrm{cm}^{3}\right)$ & 0.8 \\
Production casing pressure at $2500 \mathrm{~m}, P_{t}(\mathrm{MPa})$ & 10.76 \\
Resistance to extrusion strength, $P_{r}(\mathrm{MPa})$ & 36.54 \\
Safety coefficient of resistance to extrusion, $K_{c}$ & 1.105 \\
The maximum safe lift depth, $L_{\max }(\mathrm{m})$ & 4180.2 \\
\hline
\end{tabular}

\subsubsection{Safety analysis of the newly selected well completion string in the Algeria $438 B$ block}

The part of the new well completion string that resists the formation external extrusion pressure is composed of two segments: the $\Phi 244.5 \mathrm{~mm}$ technical casing and the $\Phi 177.8 \mathrm{~mm}$ production casing. The $\Phi 177.8 \mathrm{~mm}$ production casing is supported by the $\Phi 244.5 \mathrm{~mm}$ technical casing and does not extend to the wellhead. However, compared to the $\Phi 177.8 \mathrm{~mm}$ production casing, the $\Phi 244.5 \mathrm{~mm}$ technical casing resists a smaller load of the external extrusion, thus making it is one of the weaker parts resisting the external extrusion in the well body. First, a partial analysis example is considered and then, an overall analysis is performed.

Safety analysis of the partial technical casing ( $\Phi 244.5 \mathrm{~mm})$. The technical casing of $\Phi 244.5 \mathrm{~mm}$ in the Algeria 438B block oilfield is primarily composed of P110 steel grade $(69.94 \mathrm{~kg} / \mathrm{m})$. According to the casing collapse pressure table of API $\left(P_{r}=36.54 \mathrm{MPa}\right)$, there is no casing extrusion deformation problem $(4180.2 \mathrm{~m}$ $>2500 \mathrm{~m}$ ) for the $\Phi 244.5 \mathrm{~mm}$ technical casing when the depth of the gas injection ranges from 0 to $2500 \mathrm{~m}$. The calculated results are shown in Table 1 . There is no casing extrusion deformation problem $(2808.7 \mathrm{~m}>$ $2500 \mathrm{~m}$ ) for the $\Phi 244.5 \mathrm{~mm}$ technical casing at depths between 0 and $2500 \mathrm{~m}$, even if there is no static liquid column in the shut-in state. The calculated results are shown in Table 2.

The calculation results show that the lowest wellhead casing pressure in the production state is 8.9 MPa. Note that the maximum gas injection pressure that a wellhead can provide is $11 \mathrm{MPa}$. The design method of gas lift uses an equal pressure drop. Seven valves are distributed in a $3500 \mathrm{~m}$ well. The pressure drop of each valve is $0.3 \mathrm{MPa}$. Therefore, the wellhead casing pressure, which is sufficient for opening the last level valve, is $8.9 \mathrm{MPa}$ and then, the calculation result of the production casing pressure, $P_{t}$, is $10.76 \mathrm{MPa}$ according to the static pressure gradient at $2500 \mathrm{~m}$. The average liquid density in the tubing is $0.8 \mathrm{~g} / \mathrm{cm}^{3}$.

Overall safety analysis of the completion string. From the wellhead (top) to the reservoir (bottom), 
Table 2. Calculation of the maximum safe lift depth when in the shut-in state.

\begin{tabular}{lc}
\hline \multicolumn{1}{c}{ Parameters } & Value \\
\hline Reservoir depth, $H_{B}(\mathrm{~m})$ & 2500 \\
Well killing fluid density, $\rho_{1}\left(\mathrm{~g} / \mathrm{cm}^{3}\right)$ & 1.25 \\
Tubing fluid density, $\rho_{2}\left(\mathrm{~g} / \mathrm{cm}^{3}\right)$ & 0.8 \\
Production casing pressure at $2500 \mathrm{~m} P_{t}(\mathrm{MPa})$ & 10.76 \\
Resistance to extrusion strength, $P_{r}(\mathrm{MPa})$ & 36.54 \\
Safety coefficient of resistance to extrusion, $K_{c}$ & 1.105 \\
The minimum static liquid surface depth, $L_{s \max }(\mathrm{m})$ & 2808.7 \\
\hline
\end{tabular}

Table 3. Calculation of the extrusion pressure resistance and the effective external pressure of the gas lift.

\begin{tabular}{|c|c|c|c|c|c|c|c|c|c|}
\hline $\begin{array}{c}\text { Depth } \\
(\mathbf{m})\end{array}$ & $\begin{array}{l}\text { Well killing } \\
\text { fluid density } \\
\qquad\left(\mathrm{g} / \mathrm{cm}^{3}\right)\end{array}$ & $\begin{array}{c}\text { The gas } \\
\text { injection } \\
\text { pressure } \\
\text { along the } \\
\text { casing } \\
\text { (MPa) }\end{array}$ & $\begin{array}{l}\text { Formation } \\
\text { extruding } \\
\text { strength } \\
(\mathrm{MPa})\end{array}$ & $\begin{array}{c}P_{r} \Phi 177.8 \mathrm{~mm} \\
\text { P110 29 } \\
\text { Pounds } / \mathrm{m} \\
(\mathrm{MPa})\end{array}$ & $\begin{array}{c}P_{r} \Phi 244.5 \mathrm{~mm} \\
\text { P110 } 47 \\
\text { Pounds } / \mathrm{m} \\
(\mathrm{MPa})\end{array}$ & $\boldsymbol{K}_{c}$ & $\begin{array}{c}\Phi 244.5 \mathrm{~mm} \\
\text { extrusion } \\
\text { pressure } \\
\text { resistance } \\
(\mathrm{MPa})\end{array}$ & $\begin{array}{c}177.8 \mathrm{~mm} \\
\text { extrusion } \\
\text { pressure } \\
\text { resistance } \\
(\mathrm{MPa})\end{array}$ & $\begin{array}{c}\text { Effective } \\
\text { extrusion } \\
\text { resistance } \\
\text { (MPa) }\end{array}$ \\
\hline 0 & 1.25 & 8.90 & 0 & 58.81 & 36.54 & 1.105 & 33.07 & 53.22 & -8.90 \\
\hline 500 & 1.25 & 9.26 & 6.13 & 58.81 & 36.54 & 1.105 & 33.07 & 53.22 & -3.13 \\
\hline 1000 & 1.25 & 9.62 & 12.26 & 58.81 & 36.54 & 1.105 & 33.07 & 53.22 & 2.64 \\
\hline 1500 & 1.25 & 9.98 & 18.39 & 58.81 & 36.54 & 1.105 & 33.07 & 53.22 & 8.41 \\
\hline 2000 & 1.25 & 10.34 & 24.52 & 58.81 & 36.54 & 1.105 & 33.07 & 53.22 & 14.18 \\
\hline 2400 & 1.25 & 10.62 & 29.42 & 58.81 & 36.54 & 1.105 & 33.07 & 53.22 & 18.80 \\
\hline 2499 & 1.25 & 10.69 & 30.63 & 58.81 & 36.54 & 1.105 & 33.07 & 53.22 & 19.94 \\
\hline 2500 & 2 & 10.70 & 49.03 & 58.81 & 36.54 & 1.105 & 33.07 & 53.22 & 38.34 \\
\hline 3000 & 2 & 11.05 & 58.84 & 58.81 & 36.54 & 1.105 & 33.07 & 53.22 & 47.79 \\
\hline 3500 & 2 & 11.41 & 68.65 & 58.81 & 36.54 & 1.105 & 33.07 & 53.22 & 57.23 \\
\hline
\end{tabular}

Table 4. Calculation of the extrusion pressure resistance and the effective external pressure when in the shut-in state.

\begin{tabular}{|c|c|c|c|c|c|c|c|c|c|}
\hline $\begin{array}{c}\text { Depth } \\
(\mathbf{m})\end{array}$ & $\begin{array}{l}\text { Well killing } \\
\text { fluid density } \\
\qquad\left(\mathrm{g} / \mathrm{cm}^{3}\right)\end{array}$ & $\begin{array}{l}\text { The static } \\
\text { liquid } \\
\text { pressure } \\
\text { annulus } \\
\text { (MPa) }\end{array}$ & $\begin{array}{l}\text { Formation } \\
\text { extruding } \\
\text { strength } \\
\text { (MPa) }\end{array}$ & $\begin{array}{c}P_{r} \Phi 177.8 \mathrm{~mm} \\
\text { P110 } 29 \\
\text { Pounds } / \mathrm{m} \\
\text { (MPa) }\end{array}$ & $\begin{array}{c}P_{r} \Phi 244.5 \mathrm{~mm} \\
\text { P110 } 47 \\
\text { Pounds } / \mathrm{m} \\
\text { (MPa) }\end{array}$ & $\boldsymbol{K}_{c}$ & $\begin{array}{c}\Phi 244.5 \mathrm{~mm} \\
\text { extrusion } \\
\text { pressure } \\
\text { resistance } \\
(\mathrm{MPa})\end{array}$ & $\begin{array}{c}\Phi 177.8 \mathrm{~mm} \\
\text { extrusion } \\
\text { pressure } \\
\text { resistance } \\
(\mathrm{MPa})\end{array}$ & $\begin{array}{c}\text { Effective } \\
\text { extrusion } \\
\text { resistance } \\
\text { (MPa) }\end{array}$ \\
\hline 0 & 1.25 & 0 & 0 & 58.81 & 36.54 & 1.105 & 33.07 & 53.22 & 0 \\
\hline 500 & 1.25 & 0 & 6.13 & 58.81 & 36.54 & 1.105 & 33.07 & 53.22 & 6.13 \\
\hline 1000 & 1.25 & 0.39 & 12.26 & 58.81 & 36.54 & 1.105 & 33.07 & 53.22 & 11.87 \\
\hline 1500 & 1.25 & 4.31 & 18.39 & 58.81 & 36.54 & 1.105 & 33.07 & 53.22 & 14.08 \\
\hline 2000 & 1.25 & 8.23 & 24.52 & 58.81 & 36.54 & 1.105 & 33.07 & 53.22 & 16.29 \\
\hline 2400 & 1.25 & 11.37 & 29.42 & 58.81 & 36.54 & 1.105 & 33.07 & 53.22 & 18.05 \\
\hline 2499 & 1.25 & 12.15 & 30.63 & 58.81 & 36.54 & 1.105 & 33.07 & 53.22 & 18.49 \\
\hline 2500 & 2 & 12.15 & 49.03 & 58.81 & 36.54 & 1.105 & 33.07 & 53.22 & 36.88 \\
\hline 3000 & 2 & 16.08 & 58.84 & 58.81 & 36.54 & 1.105 & 33.07 & 53.22 & 42.76 \\
\hline 3500 & 2 & 20 & 68.65 & 58.81 & 36.54 & 1.105 & 33.07 & 53.22 & 48.65 \\
\hline
\end{tabular}

different formations have different pressures. The Algeria 438B block oilfield operates by maintaining the reservoir pressure using water injection. The minimum pressure in the development cycle is $20 \mathrm{MPa}$. The external extrusion pressure of different casing segments can be calculated according to the well killing fluid density. The effective external extrusion pressure of the completion string both in the gas lift production state and in the shut-in state can be calculated.

By comparing effective external extrusion pres- sure and extrusion pressure between two types of strings, the safety of a completion string is determined and shown in Tables 3 and 4 and in Figures 10 and 11. From these tables and figures, the inner pressure of a completion string is low, and the string, in terms of resistance to internal pressure, is safe. In terms of resistance to external pressure, the maximum safe gas injection depth of a completion string that is produced by gas lift is $3250 \mathrm{~m}$ (Figure 10). This depth is close to the reservoir depth and can meet 
Table 5. The allowed casing depths.

\begin{tabular}{ccccccc}
\hline $\begin{array}{c}\text { Casing } \\
\text { specifications } \\
(\mathbf{m m})\end{array}$ & $\begin{array}{c}\text { Casing weight } \\
(\mathbf{k g} / \mathbf{m})\end{array}$ & $\begin{array}{c}\text { Threaded tensile } \\
\text { yield strength } \\
(\mathbf{k N})\end{array}$ & & \multicolumn{2}{c}{ The maximum depth $(\mathbf{m})$} \\
\cline { 4 - 7 } & & & $\mathbf{n = 1 . 6}$ & $\mathbf{n = 1 . 7}$ & $\boldsymbol{n = 1 . 8}$ & $\boldsymbol{n}=\mathbf{1 . 9}$ \\
\hline 244.5 & 69.94 & 4697 & 4283 & 4031 & 3807 & 3607 \\
177.8 & 43.16 & 3229 & 4771 & 4491 & 4241 & 4018 \\
\hline
\end{tabular}

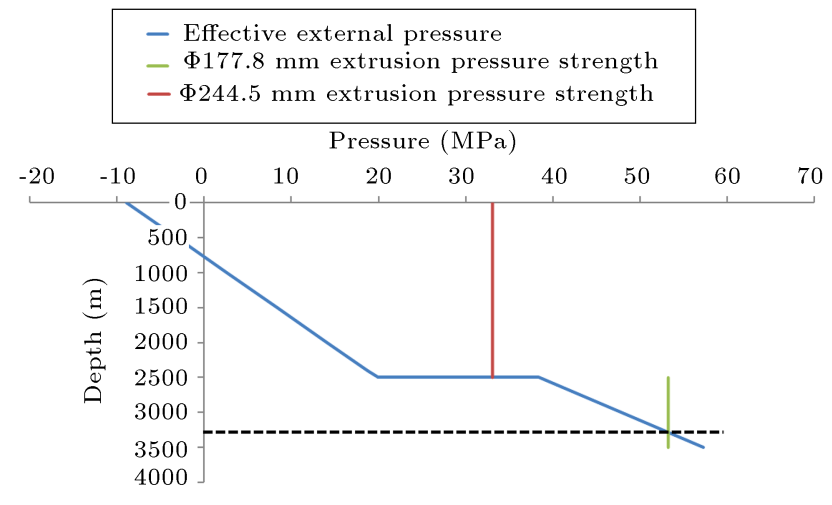

Figure 10. The relationship between the effective external pressure and the string extrusion pressure with the lift depth reaching the reservoir.

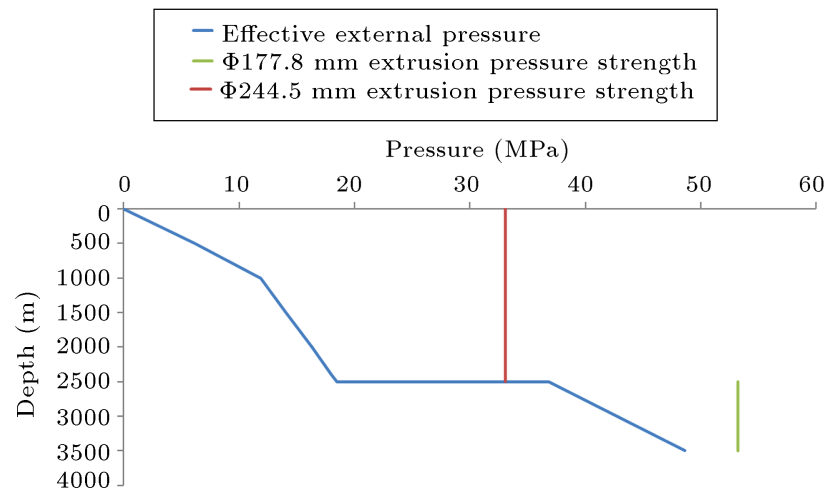

Figure 11. The relationship between the effective external pressure and the string extrusion pressure with depth in the shut-in state.

the entire development cycle requirements of gas lift. The casing extrusion pressure is greater than effective external extrusion pressure in the shut-in state, and the completion string is safe (Figure 11). Meanwhile, if gas lift production using a completion string is achieved with positive gas lift in tubing and injecting gas annulus, as shown in Figure 1a, which maintains pressure without annulus water injection, then a completion casing string may collapse.

\subsection{String tensile analysis and calculation}

The allowed depths and the loads on the string are restricted by the tensile strength of the string. The maximum depths of the casing are calculated according to the different safety factors of 1.3, 1.4, 1.5, and 1.6. The results are shown in Table 5 .

Both the $\Phi 244.5 \mathrm{~mm}$ technical casing and the $\Phi 177.8 \mathrm{~mm}$ production casing use P110 steel grade and the maximum depths are $4283 \mathrm{~m}$ and $4771 \mathrm{~m}$, respectively, when the safety coefficient is 1.6 , which meets the requirements of the completion string in the Algeria 438B block oilfield.

From the analysis of the squeeze strength, tensile strength, and resistance to internal pressure strength of the selected gas lift completion string with dual concentric tubes and positive lift, the feasibility of the gas lift well completion string design was verified.

\section{Conclusion}

A new completion string was determined to be preferable according to the development characteristics of Algeria 438B block oilfield. Compared to the completion string design used in adjacent blocks, a new gas lift completion string with dual concentric tubes and positive lift can not only decrease difficulties involved with the construction, implementation, and maintenance of gas lift production, but also improve the reliability of the system. For the new well completion string in both the gas lift production and the shut-in states, security verification for the string was provided by checking three aspects of the casing: resistance to extrusion strength, resistance to tensile strength, and resistance to internal pressure strength. The result shows that the proposed design for a gas lift completion string is feasible and the string can be applied to Algeria 438B block oilfield.

\section{Acknowledgements}

The authors thank Wei Luo for serving as the corresponding author for the article. The authors would like to acknowledge the support of the National Natural Science Fund Project (61572084) and major national projects (2017ZX05030-005, 2016ZX05056004-002, 2016ZX05046004-003) for key projects. The authors declare that there is no conflict of interest regarding the publication of this paper. The authors declare that the mentioned funding did not lead to any conflict of interests regarding the publication of this manuscript. 


\section{References}

1. Tian, J., Wang, Q., Guo, Q., et al. "Casing integrity evaluation in deep well with extreme heavy mud in tarim basin", SPE EUROPEC/EAGE Annual Conference, Vienna, Austria. SPE140982 (2011).

2. Wang, X., Mechanics Analysis and Application of the Casing String in Deep Well Cementing, Northeast Petroleum University (2011).

3. Li, J., Application Study on Casing Strength Design of Deep Horizontal Well, Yangtze University (2011).

4. Zhou, X., The Research of Casing String Strength Design in Deep Well, Xi'an Petroleum University (2012) .

5. Zhang, X., Research on Optimization Design of Casing String under Complex Conditions, Northeast Petroleum University (2013).

6. Qu, Y. and Jin, Sh. "Applications exploring of casing strength design in deep and horizontal well", Chemical Industry Management, 24, pp. 34-34 (2014).

7. Zou, Y., Strength Safety Analysis for Perforated Casing in High Temperature and High Pressure Deep Well, Xi'an Petroleum University (2012).

8. Wang, B., HPHT Completion String Mechanics Analysis and Safety Evaluation, Southwest Petroleum University (2014).

9. Wu, X., Depleted Reservoirs Gas Storage Casing Mechanical Analysis and Safety Evaluation, China University of Petroleum(East China) (2013).

10. Kinik, K. and Wojtanowicz, A., Identifying Environmental Risk of Sustained Casing Pressure, Wiertnictwo, SPE143713 (2011).

11. Rocha-Valadez, T., Mentzer, R.A., Hasan, A.R., et al. "Inherently safer sustained casing pressure testing for well integrity evaluation", Journal of Loss Prevention in the Process Industries, 29(1), pp. 209-215 (2014).

12. Salehabadi, M., Jin, M., Yang, J., et al. "Effect of casing eccentricity on casing stability analysis in wellbores drilled in gas hydrate bearing sediments", SPE EUROPEC/EAGE Annual Conference, Barcelona, Spain, SPE131236 (2010).

13. Deng, K., Liu, W., Xia, T., et al. "Experimental study the collapse failure mechanism of cemented casing under non-uniform load", Engineering Failure Analysis, 73, pp. 1-10 (2017).

14. Farshad, F.F., Garber, J.D., Rieke, H.H., et al. "Predicting corrosion in pipelines, oil wells and gas wells; a computer modeling approach", Scientia Iranica, 17(1), pp. 86-96 (2010).

15. Kannojiya, V. and Kumar, S. "Assessment of optimum slurry pipe design for minimum erosion", Scientia Iranica, 27(5), pp. 2409-2418 (2020).

16. Kiran, R., Catalin, T., Younas, D., et al. "Identification and evaluation of well integrity and causes of failure of well integrity barriers (A review)", Journal of Natural Gas Science and Engineering, 45, pp. 511526 (2017).

17. Shen, C. "Transient dynamics study on casing deformation resulted from lost circulation in low-pressure formation in the Yuanba Gasfield, Sichuan Basin", Natural Gas Industry, 2(4), pp. 347-353 (2015).

18. Liu, J., Guo, X., Liu, Z., et al. "Pressure field investigation into oil \& gas wellbore during perforating shaped charge explosion", Journal of Petroleum Science and Engineering, 172, pp. 1235-1247 (2019).

19. Zhang, Z., Shao, L., Zhang, Q., et al. "Environmentally assisted cracking performance research on casing for sour gas wells", Journal of Petroleum Science 8 Engineering, 158, pp. 729-738 (2017).

20. Grassick, D., Kallos, P., Jardine, I., et al. "Risk analysis of single and dual-string gas-lift completions", Journal of Petroleum Technology, (USA), 42(11), pp. 1374-1419 (1990).

21. Grassick, D.D., Kallos, P.S., Dean, S., et al. "Blowout risk analysis of gas-lift completions", Spe Production Engineering, 7(2), pp. 172-180 (1992).

22. Zhang, F., Ding, L., and Yang, X. "Prediction of pressure between packers of staged fracturing pipe strings in high-pressure deep wells and its application", Natural Gas Industry, 2(2-3), pp. 252-256 (2015).

23. Li, Z., Zhang, C., and Song, G. "Research advances and debates on tubular mechanics in oil and gas wells", Journal of Petroleum Science \& Engineering, 151, pp. 194-212 (2017).

24. Liu, K., Gao, D., and Arash, D.T. "Analysis on integrity of cement sheath in the vertical section of wells during hydraulic fracturing", Journal of Petroleum Science and Engineering, 168, pp. 370-379 (2018).

\section{Biographies}

Wei Luo was born in Xiantao, Hubei Province, China in 1986. He received his $\mathrm{PhD}$ degree from Yangtze University in 2015. He is a Teacher in Petroleum Engineering at Yangtze University. $\mathrm{He}$ is mainly active in the study on low permeability development technology, oil production technology for horizontal well and gas lift oil production technology, etc.

Jing Wen was born in Jingzhou, Hubei Province, China in 1983. She is a Teacher at Logging Technology and Engineering Research Institute of Yangtze University. She received his $\mathrm{PhD}$ degree from Chengdu University of Technology in 2019. She is mainly engaged in reservoir engineering and reservoir characteristics research.

Weilin Qi was born in August 1983 in Xi'an, Shaanxi Province. He graduated from Xi'an Petroleum University in material forming and control engineering with 
a BSc degree. He is mainly engaged in the research and technical service of tools related to gas lift oil production.

Ming Yang was born in Neijiang, Sichuan Province,
China in 1981. He received his BSc of Engineering degree from Southwest Petroleum University in 1999 and 2003. He is currently a Senior Engineer of CNPC. His research interests include development geology, oil production engineering, and production processes. 